Research Article

\title{
Evaluation of Corrosion Inhibition of 316L Stainless Steel by Permanganate Ions in Chloride Solution
}

\author{
Fahd Arbaoui ${ }^{*}$, Sid Ahmed Amzert ${ }^{1}$, Mohamed Nadir Boucherit ${ }^{2}$, Salah Hanini ${ }^{3}$, \\ Khaoula Ghezali ${ }^{4}$
}

\author{
${ }^{1}$ Chemistry Department, Nuclear Research Centre of Birine, BO: 180 Ain Oussera, 17200, Djelfa, \\ Algeria. \\ ${ }^{2}$ Nuclear Engineering Research and Development Unit, BO 399 Algiers, Algeria. \\ ${ }_{3}^{3}$ Yahia Fares University, Ain-D’heb, 26000, Medea, Algeria. \\ ${ }^{4}$ Crystallography Laboratory, Physics Department, Faculty of Exact Sciences, Mentouri Brothers \\ University, Route Ain El Bey, Constantine 25000, Algeria.
}

Received: $2^{\text {nd }}$ March 2021; Revised: 8h $^{\text {th }}$ April 2021; Accepted: $9^{\text {th }}$ April 2021

Available online: $12^{\text {nd }}$ April 2021; Published regularly: June 2021

\section{Abstract}

The efficiency of permanganates to inhibit the scale deposit captured the attention for more investigation on their role as corrosion inhibitor. In this article, the effect of permanganate as corrosion inhibitor on 316L stainless steel in $\mathrm{NaCl}$ solution is investigated. The potentiodynamic polarization and electrochemical impedance spectroscopy (EIS) have been performed by varying the electrode stirring speed, the concentration of permanganate ions, $\mathrm{pH}$ and the temperature. The results show that the permanganate ions increase the cathodic and anodic currents under effect of stirring speed, due to oxygen reduction reaction and the reduction of permanganate ions. Electrochemical results indicate that the deposit of manganese oxide $\left(\mathrm{MnO}_{2}\right)$ inhibits the pitting corrosion. The inhibition efficiency is up to $98 \%$ for $10^{-4} \mathrm{~mol} . \mathrm{dm}^{-3}$ of permanganate. The temperature reduces the effectiveness of permanganates against pitting corrosion, the pitting potential shifts cathodically from $+0.395 \mathrm{~V}$ vs. Saturated Calomel Electrode (SCE) at $298 \mathrm{~K}$ to $+0.275 \mathrm{~V}$ vs. SCE at $343 \mathrm{~K}$. Surface morphology of the deposit oxide films and electrode are studied by emission scanning electron microscopy, X-ray diffraction, Fourier transform infrared and Differential Scanning Calorimetry. The analysis of the deposit layer by X-ray diffraction revealed the presence of $\delta$ - $\mathrm{MnO}_{2}$ form, with a crystallite size of $3.17 \mathrm{~nm}$.

Copyright (C) 2021 by Authors, Published by BCREC Group. This is an open access article under the CC BY-SA License (https://creativecommons.org/licenses/by-sa/4.0).

Keywords: pitting corrosion; stainless steel; permanganate; manganese oxide; corrosion inhibitor

How to Cite: F. Arbaoui, S.A. Amzert, M.N. Boucherit, S. Hanini, K. Ghezali (2021). Evaluation of Corrosion Inhibition of 316L Stainless Steel by Permanganate Ions in Chloride Solution. Bulletin of Chemical Reaction Engineering \& Catalysis, 16(2), 234-243 (doi:10.9767/bcrec.16.2.10504.234-243)

Permalink/DOI: https://doi.org/10.9767/bcrec.16.2.10504.234-243

\section{Introduction}

In a nuclear installation, operational safety is a major and permanent concern. The issue concerns all the installation's components,

\footnotetext{
* Corresponding Author.

Email: arbaoui.fahd@gmail.com (Arbaoui, F);

Telp.: +213672106104
}

whether they are in direct contact with the reactor core or in an auxiliary structure [1]. Cooling circuits are among the major components that are subject to rigorous monitoring [2]. The material chosen for the pipes of the cooling circuits takes into account the volume of the circuit, the operating conditions of the installation and the desired lifetime. When fluid flows the metal/fluid interface becomes the most vulnera- 
ble region of the circuit [3]. This interface can be the site of both corrosion phenomena and scale deposits. The challenge is to reduce the risks of both corrosion and scale deposits [4].

To prevent corrosion of the cooling circuits, it was recommended the use of corrosion inhibitors, which must be efficient, stable, inexpensive, but also non-toxic to the environment of the installation. Oxyanions such as molybdate, tungstate and vanadate which are similar to chromate are known to have a corrosion inhibiting effect on various materials [5-8]. The majority of these corrosion inhibitors increase the $\mathrm{pH}$, which reduces the oxidation of the metal and consequently promotes the formation of scale deposit.

Permanganates are oxyanions known to be corrosion inhibitors with low toxicity and strong oxidants power [9-13]. It is used in acidic medium to decontamination of radionuclide in heat exchanger of nuclear power plant and it can inhibits pitting corrosion through the deposition of manganese oxide $\mathrm{MnO}_{2}$ [14]. Several recent studies use the permanganate ions such as corrosion inhibitor on different materials. Osipenko et al. have showed that the permanganate in acidic media containing chloride ions inhibit the corrosion of aluminum alloy AD31 [15]. Sung-Mao Hung et al. studied the coating of a magnesium-lithium alloy LZ91, using a strongly acidic permanganate solution, the corrosion resistance of this alloy was significantly improved by the thin and uniform coating, which consisted of $\mathrm{MgO}, \mathrm{MnO}_{2}$ and $\mathrm{Mg}(\mathrm{OH})_{2}$ [10]. Yanqi Wang et al. showed that the permanganate ions exhibited a promising inhibition $(>98 \%)$ on galvanized steel in concrete leading to the formation of a protective film of $\mathrm{CaMnO}_{4}$ and $\mathrm{Ca}\left(\mathrm{HMnO}_{2}\right)_{2}$ [16].

In our previous study, we demonstrated that the electrochemical reduction of permanganate on a stainless steel surface can lead to the formation of manganese oxides which can substantially reduce nucleation and growth of scale deposits. The manganese oxide appears at a more anodic potential than the potential for scale formation. This oxide is sufficiently conductive; it does not affect the reduction of dissolved oxygen which is necessary for the growth of scale deposits. Despite this, the scale deposits formed in the presence of permanganates are very poorly adherent and also very porous [17].

In view of the effect of permanganate ions for the inhibition of scale deposit on 316L stainless steel, we study in the present work the corrosion inhibition of $316 \mathrm{~L}$ stainless steel using rotating electrode by permanganate ions in a chloride solution. We discuss the influence of various parameters on the open circuit potential and anodic and cathodic currents. We analyze the reduction of permanganate and the formation of manganese oxides on the steel surface. These oxides are then characterized by electrochemical impedance (EIS), scanning electron microscopy (SEM-EDS), X-ray diffraction (XRD), Fourier transform infrared (FTIR) and Differential Scanning Calorimetry (DSC).

\section{Materials and methods}

\subsection{Chemicals and Reagents}

Deionized water and analytical reagent grade (Sigma-Aldrich), sodium chloride, $\mathrm{NaCl}$ (99\%), potassium permanganate, $\mathrm{KMnO}_{4}(99 \%)$ are used to prepare all solutions. For adjustment of $\mathrm{pH}$, we used a dilute solution prepared from $\mathrm{HCl}(37 \%)$ and $\mathrm{NaOH}(97 \%)$.

\subsection{Materials Preparation}

The sample selected for the study was a 316L stainless steel with an alloying element composition of $0.018 \% \mathrm{C}, 0.400 \% \mathrm{Si}, 1.740$ $\% \mathrm{Mn}, 0.038 \% \mathrm{P}, 0.029 \% \mathrm{~S}, 16.550 \% \mathrm{Cr}, 10.060$ $\% \mathrm{Ni}, 2.030 \% \mathrm{Mo}, 0.014 \% \mathrm{Nb}, 0.067 \% \mathrm{~N}, 0.450$ $\% \mathrm{Cu}, 0.160 \% \mathrm{Co}$, and $\mathrm{Fe}$ remainder (in wt\%). The stainless steel sample is placed in a rotary motor Model EDI101 connected with a stirring speed controller Radiometer; it is coated with PTFE shroud as shown in Figure 1.

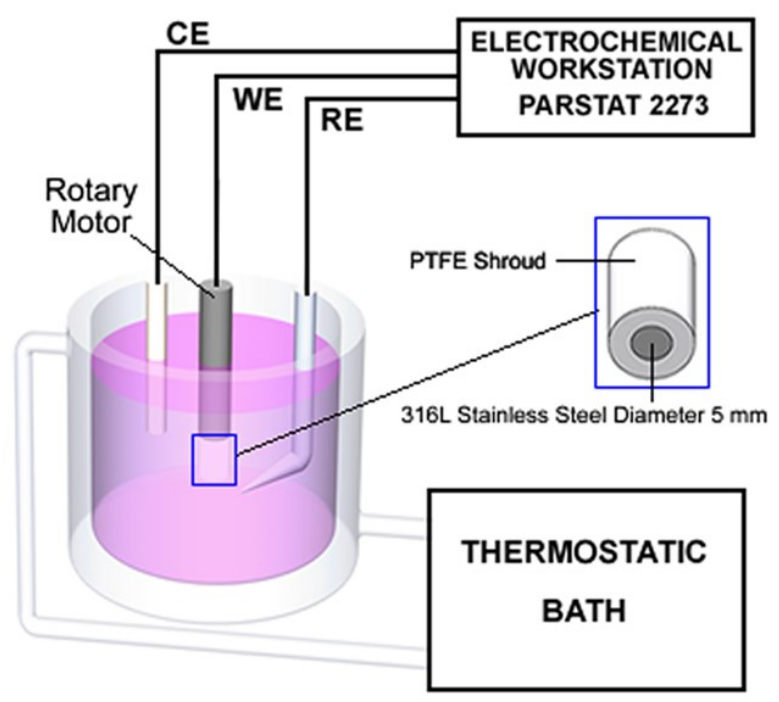

Figure 1. Illustration of a three-electrode electrochemical thermostatic cell system with rotating working electrode. 


\subsection{Electrochemical Methods}

All the electrochemical measurements were performed in a thermostatic cell $(250 \mathrm{ml})$ containing three electrodes: the rotating disk electrode (RDE) as working electrode (WE) with a diameter of $5 \mathrm{~mm}$, the reference electrode (RE) was the Saturated Calomel Electrode (SCE) and the auxiliary electrode (CE) made of a platinum sheet as shown in Figure 1. The surface of working electrode was prepared using abrasive silicon carbide emery papers (SiC) 1200 grade and then rinsed with deionized water, cleaned and degreased with acetone.

All electrochemical Polarization tests were performed in a Parstat 2273 (EG\&G PARC) Potentiostat/Galvanostat, and controlled by PowerSuite software. The open circuit potential (OCP) of 316L stainless steel sample was recorded for six hours for each solution. Potentiodynamic polarizations tests were performed from -1 to $1 \mathrm{~V}$ us SCE with a rate scan of 1 $\mathrm{mVs}^{-1}$ for each solution. The electrochemical impedance spectroscopy (EIS) measurements were performed after different time of immersion at the OCP potential in the frequency range $100 \mathrm{kHz}$ to $10 \mathrm{mHz}$ and with potential perturbation amplitude of $10 \mathrm{mV}$.

\subsection{Characterization of Deposit}

The formed deposit on the electrode surface after potentiodynamic polarization tests from -1 to $+1 \mathrm{~V}$ vs SCE with and without permanganate ions was characterized by scanning electron microscopy coupled with energy dispersive spectroscopy (SEM-EDS), and X-ray diffraction

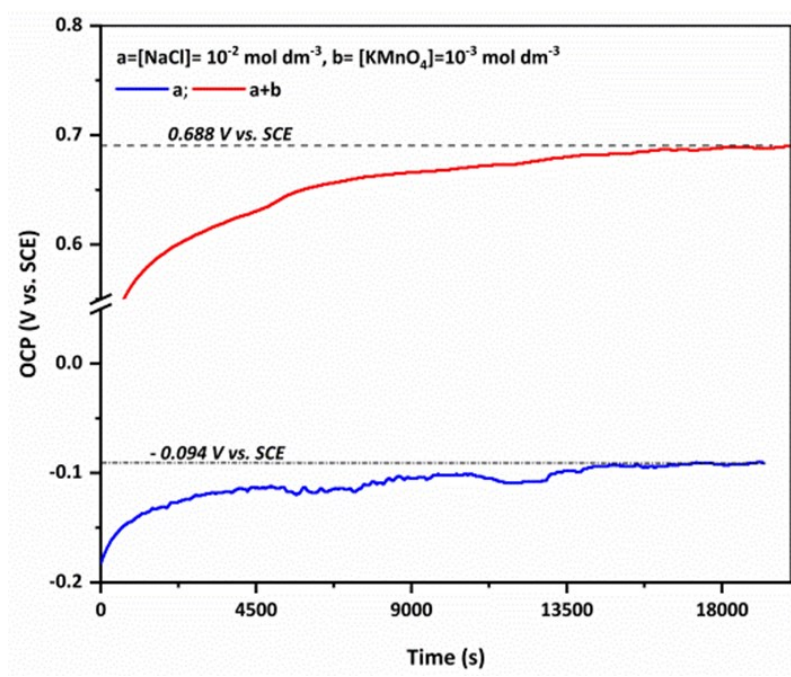

Figure 2. Evolution of the open circuit potential, OCP of $316 \mathrm{~L}$ stainles steel in chloride solutions with and without permanganate ions.
(XRD). The potentiodynamic tests were performed in solutions containing $10^{-2} \mathrm{~mol}_{\mathrm{dm}} \mathrm{dm}^{-3}$ of $\mathrm{NaCl}$, stirring speed $1500 \mathrm{rpm}$, temperature $298 \mathrm{~K}$, at $\mathrm{pH}=6.50$ and $10^{-2} \mathrm{~mol} . \mathrm{dm}^{-3}$ of permanganate ions. The morphologies of electrode surface and deposits were investigated by scanning electron microscopy SEM-EDS Quanta 250 microscope. This equipment also gives the possibility to characterize qualitatively the composition of different deposit layers with the energy dispersive spectroscopy (EDS) technique.

The diffraction patterns were registered with a diffractometer model PANalytical XPert PW1500 equipped with a hot diffraction chamber (HTK1200 Anton Paar) with a $\mathrm{Cu}-\mathrm{K \alpha}$ radiation $(\lambda=0.15405 \mathrm{~nm}),(45 \mathrm{kV} / 40 \mathrm{~mA})$ and the counting time was $3 \mathrm{~s}$ per $0.02^{\circ} 2 \theta$ angular step. The scan was performed between $20^{\circ} \leq 2 \theta \leq 75^{\circ}$. These data were processed to determine the size of the crystallites and the crystallographic parameters, including the micro strain.

The deposit obtained on the electrode surface, under the same previous conditions, was scraped and collected in order to be characterized by Fourier Transform infrared spectrometry (FTIR) and Differential Scanning Calorimetry (DSC). Infrared (IR) measurements were carried out by a Fourier transform infrared spectrometer FTIR (INFRALUM FT-02). The deposit is ground and mixed with $\mathrm{KBr}$ (with high purity $99.90 \%$ used as the diluent) dried at $393 \mathrm{~K}$ for $24 \mathrm{~h}$ to remove the adsorbed water. The mass ratio is: $99.70 \% \mathrm{KBr}$ and $0.30 \%$ deposit. The mixed powders are pressed by a Tablet Press Machine (Specac) at $10 \mathrm{MPa}$, to obtain pellets with diameter of $13 \mathrm{~mm}$. The spectrum was collected under ambient conditions in the range of 4000 to $400 \mathrm{~cm}^{-1}$ with a resolution of $4 \mathrm{~cm}^{-1}$. It was saved and treated by SpectraLum software. Differential Scanning Calorimetry (DSC) was carried out on a SetsysEvolution 1500 with heating rate of $15 \mathrm{~K} . \mathrm{min}^{-1}$ from $298 \mathrm{~K}$ to $1073 \mathrm{~K}$, the experiments were carried out in a highly pure argon atmosphere, data are collected and processed by SETSOFT 2000 Software.

\section{Results and Discussions}

Figure 2 displays the evolution of the OCP of $316 \mathrm{~L}$ stainless steel in chloride solution $10^{-2}$ mol. $\mathrm{dm}^{-3}$ without and with permanganate ions $10^{-3}$ mol. $\mathrm{dm}^{-3}$ during six hours of immersion. As shown, without permanganate ions, the OCP shifts anodically from $-0.180 \mathrm{~V}$ vs SCE to $-0.094 \mathrm{~V}$ vs SCE. With presence of permanga- 
nate ions the OCP displaces anodically from $+0.475 \mathrm{~V}$ vs SCE to $+0.688 \mathrm{~V}$ vs SCE.

The anodic evolution of OCP potential in the presence of chloride ions during the immersion time indicates the formation of a passive film which contains two layers: an outer layer containing Fe and Mo and an inner layer containing chromium according to Wang et al. [18]. With permanganate ions, the OCP evolve to $+0.688 \mathrm{~V}$ vs $\mathrm{SCE}$, which indicates that the steel is more resistant to corrosion. This displacement can be attributed to the permanganate ions which promote the formation of a more protective layer [19].

Figure 3 shows the effect of stirring speed on the evolution of the potentiodynamic polarization curves with permanganate ions $10^{-2}$

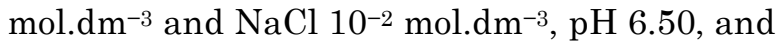
at $298 \mathrm{~K}$. In stagnant solution, permanganate ions $10^{-2}$ mol. $\mathrm{dm}^{-3}$ shifts anodically the corrosion potential $\left(E_{\text {corr }}\right)$ of stainless steel from $-0.148 \mathrm{~V}$ vs SCE to $+0.290 \mathrm{~V}$ vs SCE. It is observed that the stirring speed influence slightly the values of $E_{\text {corr }}$ which is located between 0.290 and $0.360 \mathrm{~V}$ us SCE due to the oxygen reduction reaction (ORR). The current density of cathodic and anodic parts is proportional to the stirring speed. At cathodic potentials two kinds of reactions could take place:

- The ORR, dependent on the diffusion of oxygen under the effect of stirring speed, according to two mechanisms: 2 electrons at low speed and 4 electrons at high speed. These reactions make the local $\mathrm{pH}$ more alkaline [17].

- The successive reduction of permanganate to manganate and hypomanganate takes place according to the reactions [20]:

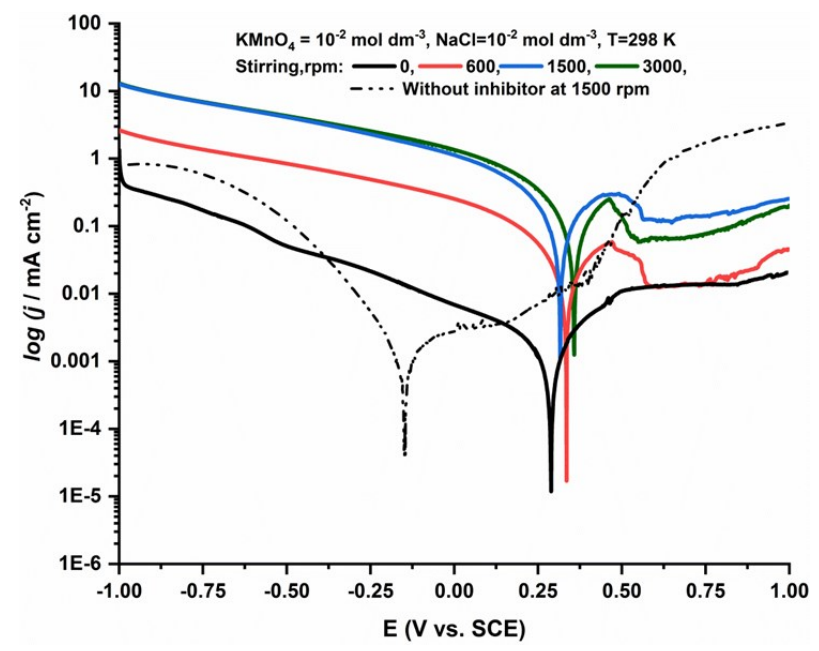

Figure 3. Potentiodynamic curves of $316 \mathrm{~L}$ stainles steel in the presence of chloride and permanganate ions as a function of stirring speed of the solution.

$$
\begin{aligned}
& \mathrm{MnO}_{4^{-}}+e^{-} \rightarrow \mathrm{MnO}_{4} 2^{-} \\
& \mathrm{MnO}_{4^{2-}}+e^{-} \rightarrow \mathrm{MnO}_{4^{3-}}
\end{aligned}
$$

The current density of anodic peak appears around $+0.465 \mathrm{~V}$ vs SCE, increases with stirring speed. This peak could be assigned to the reduction of permanganate into manganese oxide such as the follow reaction [20]:

$$
\mathrm{MnO}_{4}^{-}+4 \mathrm{H}^{+}+3 e^{-} \rightarrow \mathrm{MnO}_{2}+2 \mathrm{H}_{2} \mathrm{O}
$$

Figure 4 shows the effect of permanganate ions on the potentiodynamic polarization curves of stainless steel, by fixing the speed stirring $1500 \mathrm{rpm}$, the $\mathrm{pH}=6.50$, the temperature $298 \mathrm{~K}$ and the concentration of $\mathrm{NaCl} 10^{-2}$ mol. $\mathrm{dm}^{-3}$. When the concentration of permanganate ions increases $E_{\text {corr }}$ shifts anodically from -0.148 to $+0.400 \mathrm{~V}$ vs SCE. In cathodic parts of voltammogram, it is noted that the permanganate ions increase the cathodic current. The anodic current without permanganate ions is greater only compared to solution containing the smallest amount of a $\mathrm{MnO}_{4}^{-}$in electrolyte.

The increasing of inhibitor concentration beyond $10^{-3} \mathrm{~mol} . \mathrm{dm}^{-3}$, the anodic peak of reaction (3) becomes more apparent. It can be seen that permanganate ions displace anodically the pitting potential from $+0.443 \mathrm{~V}$ vs SCE (without permanganate) to total inhibition at a concentration of $10^{-2} \mathrm{~mol} \cdot \mathrm{dm}^{-3}$. SEM micrograph of electrode surface after potentiodynamic polarization test in $\mathrm{NaCl}$ solution $10^{-2} \mathrm{~mol}^{-\mathrm{dm}^{-3}}$ without permanganate in Figure 5, shows the presence of pits on the surface of stainless steel electrode.

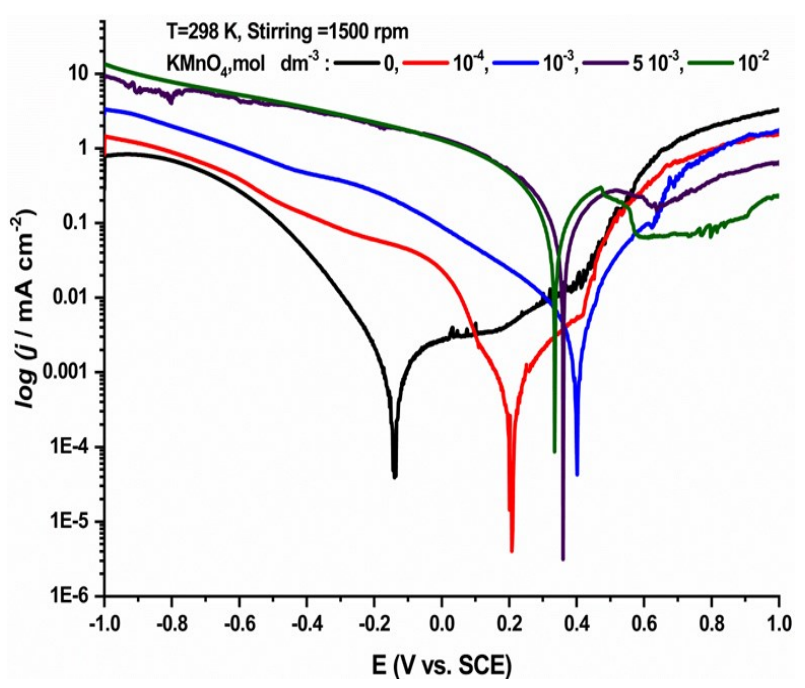

Figure 4. Potentiodynamic curves of $316 \mathrm{~L}$ stainles steel in chloride solution with various permanganate concentrations. 
Table 1 gathers the electrochemical parameters according to the Tafel extrapolation to obtain the polarization resistance $R_{p}$, the corrosion current $I_{c o r r}$, the anodic and cathodic slopes and the inhibition efficiency $I E \%$, which is calculated by comparing the corrosion current recorded with and without permanganate ions. The inhibition efficiency is expressed according to Kuznetsov et al. [21]:

$$
I E \%=100\left(1-\frac{I_{\text {Corr_inhibitor }}}{I_{\text {Corr_without_inhibitor }}}\right)
$$

For permanganates ions concentrations of $10^{-4}$ mol. $\mathrm{dm}^{-3}$ and $10^{-3} \mathrm{~mol} . \mathrm{dm}^{-3}$, the inhibition efficiency is $98.58 \%$ and $90.87 \%$ respectively. This confirms that permanganates can be used as general corrosion inhibitors. However, for high concentrations above $10^{-3} \mathrm{~mol} . \mathrm{dm}^{-3}$, calculation of the inhibition efficiency gave outliers, this is due to the anode peak at $+0.465 \mathrm{~V}$ vs SCE which is very close to the corrosion potential and which makes the calculation of Tafel parameters impossible in the potential range \pm 0.3 $\mathrm{V}$ about $E_{\text {corr. }}$.

Figure 6 gathers potentiodynamic polarization curves of $316 \mathrm{~L}$ stainless steel obtained in a solution of $10^{-3} \mathrm{~mol}_{\mathrm{dm}} \mathrm{dm}^{-3}$ permanganate and $10^{-2} \mathrm{~mol} \cdot \mathrm{dm}^{-3}$ chlorides, by fixing the stirring speed at $1500 \mathrm{rpm}$ in different $\mathrm{pH}$ values: 2.17 , 7.00 and 11.55. In acidic medium $\mathrm{pH}=2.17$,

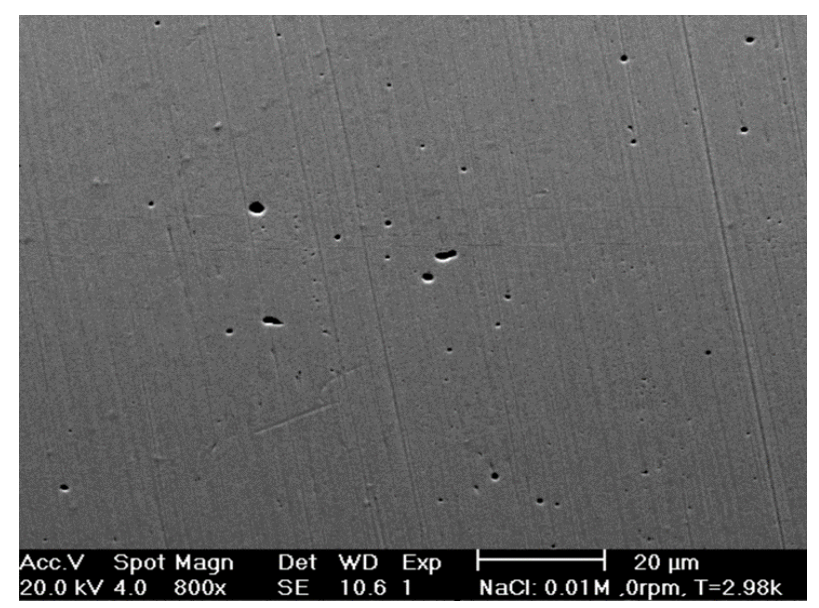

Figure 5. SEM micrograph of electrode surface in chloride solution $10^{-2} \mathrm{~mol} . \mathrm{dm}^{-3}$, stirring speed $0 \mathrm{rpm}$ at $298 \mathrm{~K}$, without permanganate. the corrosion potential shifts anodically to $+0.455 \mathrm{~V}$ vs SCE, with an increase in anodic and cathodic currents compared to the voltammogram at $\mathrm{pH}=7.00(+0.342 \mathrm{~V}$ vs SCE). In alkaline solution at $\mathrm{pH}=11.55$, the corrosion potential shifts cathodically to $+0.074 \mathrm{~V}$ vs SCE.

Permanganate ions in aqueous solution are stable regardless of the $\mathrm{pH}$ for potential greater than the potential of water oxidation [22]. In acidic medium the permanganate ions are reduced to $\mathrm{MnO}_{2}$ and oxidize the metal according to the following [14]:

$$
\mathrm{MnO}_{4}^{-}+4 \mathrm{H}^{+}+\frac{3}{x} \mathrm{M} \rightarrow \mathrm{MnO}_{2}+2 \mathrm{H}_{2} \mathrm{O}+\frac{3}{x} M^{x+}
$$

This reaction takes place in several stages of transfer of one electron giving rise to intermediate oxidation states:

$$
M n^{V I I} \rightarrow M^{V I} \rightarrow M n^{V} \rightarrow M n^{I V} \rightarrow M n^{I I I}
$$

Whatever the oxidation state of the manganese, it contributes to the formation of $\mathrm{MnO}_{2}$ [22]. However, in acidic medium, in addition to the dissolved oxygen reduction reaction and those permanganates, one should consider the hydrated proton reduction reaction $\mathrm{H}_{3} \mathrm{O}^{+}$according to the reaction [22]:

$$
\mathrm{H}_{3} \mathrm{O}^{+}+e^{-} \rightarrow 2 \mathrm{H}_{2} \mathrm{O}+\mathrm{H}
$$

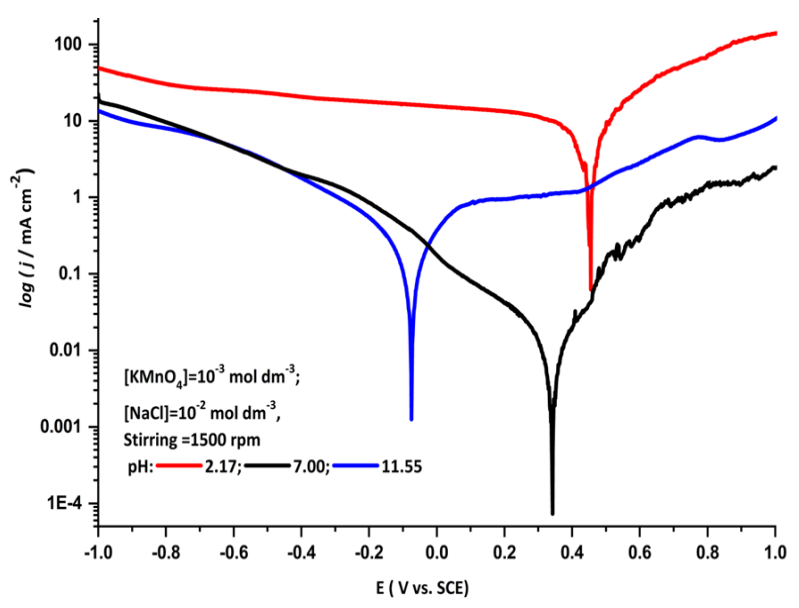

Figure 6. Potentiodynamic curves of 316L stainles steel in the presence of chloride and permanganate ions as a function of the $\mathrm{pH}$.

Table 1. The electrochemical parameters deduced from the potentiodynamic curves.

\begin{tabular}{cccccccc}
\hline $\begin{array}{c}\mathrm{KMnO}_{4} \\
\left(\mathrm{mol.dm}^{-3}\right)\end{array}$ & $\begin{array}{c}\mathrm{NaCl} \\
\left(\mathrm{mol} . d m^{-3}\right)\end{array}$ & $\begin{array}{c}E_{\text {corr }} \\
(\mathrm{V})\end{array}$ & $\begin{array}{c}j_{\text {corr }} \\
(\mu \mathrm{A})\end{array}$ & $\begin{array}{c}\beta_{a} \\
\left(\mathrm{~V} . \mathrm{dec}^{-1}\right)\end{array}$ & $\begin{array}{c}\beta_{c} \\
\left(\mathrm{~V} . \mathrm{dec}^{-1}\right)\end{array}$ & $\begin{array}{c}R_{p} \\
(\mathrm{k} \Omega)\end{array}$ & $\begin{array}{c}I E \\
(\%)\end{array}$ \\
\hline 0 & $10^{-2}$ & -0.148 & 4.570 & 0.060 & 0.026 & 270.005 & \\
$10^{-4}$ & $10^{-2}$ & 0.206 & 0.065 & 0.092 & 0.140 & 239.128 & 98.580 \\
$10^{-3}$ & $10^{-2}$ & 0.401 & 0.780 & 0.122 & 0.224 & 41.206 & 90.870 \\
\hline
\end{tabular}


In alkaline medium the permanganate ions are transformed into manganite ions followed by a transformation into $\mathrm{MnO}_{2}$ [23-26]:

$$
2 \mathrm{MnO}_{4}^{-}+\mathrm{MnO}_{2}+4 \mathrm{OH}^{-} \rightleftharpoons 3 \mathrm{MnO}_{2^{2-}}+2 \mathrm{H}_{2} \mathrm{O}
$$

In acidic medium, it was noted a considerable increase in the anodic current after the pitting potential, unlike permanganate ions in an alkaline or neutral medium.

Figure 7 shows the voltammograms of $316 \mathrm{~L}$ stainless steel, obtained in a solution of $10^{-3}$ mol.dm ${ }^{-3}$ permanganate and $10^{-2} \mathrm{~mol} \cdot \mathrm{dm}^{-3}$ chlorides, by fixing the stirring speed at 1500 rpm, for different solution temperatures: 298, $303,313,323$ and $343 \mathrm{~K}$. Under effect of temperature, the $E_{\text {corr }}$ shifts cathodically from +0.400 to $+0.275 \mathrm{~V}$ vs SCE. It can be seen that the anodic currents increase with temperature, due to the decrease in the energy barrier with temperature for iron oxidation reactions [27]. The pitting potential decreases from $+0.620 \mathrm{~V}$ vs SCE at $298 \mathrm{~K}$ to $+0.320 \mathrm{~V}$ vs SCE at $343 \mathrm{~K}$. In the cathodic part of the voltammograms, there are disturbances of the cathodic currents at high temperatures. The observed peaks in cathodic currents prove the presence of reduction reactions of permanganate [17]. The analysis by Electrochemical Impedances Spectroscopy (EIS) provides additional information concerning the steel/film/electrolyte system. Figure

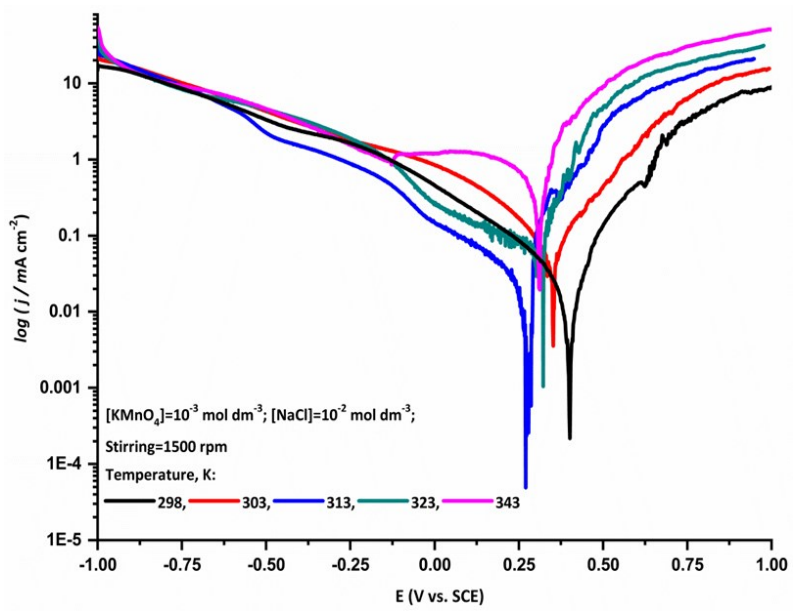

Figure 7. Potentiodynamic curves of $316 \mathrm{~L}$ stainles steel in the presence of permanganate at different temperatures.
8 presents the Nyquist diagrams recording of stainless steel and the fitted curve, obtained in a solution of $5 \times 10^{-3}$ mol. $\mathrm{dm}^{-3}$ permanganate and $2 \times 10^{-2}$ mol.dm ${ }^{-3}$ chlorides, at OCP potential and without stirring in different immersion periods between 1 hour and 24 hours.

The equivalent circuit chosen with two loops is similar to the equivalent circuit used for modelling the inhibition of cupronickel steel by permanganate ions [14], with solution resistance $R_{s}$. The first circuit describes the deposition of manganese dioxide with a resistance $R_{f}$ and a capacitance $C_{f}$, the second circuit describes the reactions that take place at the interface with the steel where $R_{c t}$ represents the charge transfer resistance and $C_{d l}$ the double layer capacitance. It is remarkable that the Nyquist diagrams progress to the axis of the imaginary impedances (i.e. dominance of the capacitive effect) due to porous morphology of manganese dioxide deposit. The results of the equivalent circuit parameters by fitting Nyquist plots are presented in Table 2.

The fitting of the Nyquist diagrams was obtained with errors $\chi^{2}$ not exceeding $5 \%$. The increased capacity and resistance of the deposited film testifies the evolution of film formation as a function of immersion time. The resistance of the film changes from $66 \mathrm{~kW}$ after 1 hour of immersion to $142 \mathrm{k} \Omega$ after 24 hours.

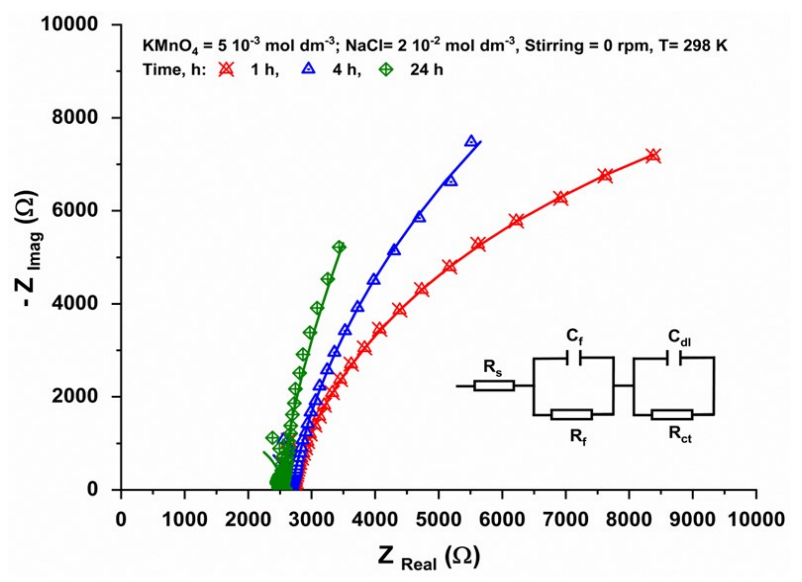

Figure 8. Nyquist plot and fitting curve of 316L stainles steel in the presence of permanganate and chlorides ions as function as immersion time.

Table 2. The Equivalent circuit parameters by fitting Nyquist plots.

\begin{tabular}{ccccccc}
\hline & $R s(\Omega)$ & $C_{f}(\mathrm{mF})$ & $R_{f}(\Omega)$ & $C_{d l}(\mathrm{nF})$ & $R_{c t}(\Omega)$ & $\chi^{2}$ \\
\hline 01 hour & 5430 & 1.19 & 66540 & 0.19 & 8240 & 1.19 \\
04 hours & 3200 & 1.79 & 92950 & 0.31 & 10240 & 1.79 \\
24 hours & 4240 & 3.02 & 142350 & 0.63 & 8920 & 3.02 \\
\hline
\end{tabular}


Figure 9 shows a SEM image accompanied by an EDS elementary analysis of a deposit on $316 \mathrm{~L}$ stainless steel surface. The deposit layer is formed over the entire surface of the steel; the bursting of this layer is due to its dehydration. The thickness of this layer is about $8 \mu \mathrm{m}$. The white deposit on the layer results from $\mathrm{NaCl}$ crystals. Elementary analysis by EDS shows an important presence of manganese, the other elements: $\mathrm{Cr}, \mathrm{Fe}$ and $\mathrm{Ni}$ come from the chemical composition of the steel.

The X-ray diffraction of the deposit presented in Figure 10, highlights the presence of an octahedral phase where the diffraction peaks located at $25.40^{\circ}, 37.81^{\circ}$, and $65.54^{\circ}$ corre- sponding to the planes (002), (006), and (119) of the $\delta-\mathrm{MnO}_{2}$ Birnessite species [24]. The average crystallite size and micro strain are 3.17 $\mathrm{nm}$ and $4.24 \%$, respectively. In the work of Marafatto et al. for the same species was between 3 and $7 \mathrm{~nm}$ [25].

Figure 11 illustrates the FTIR spectrum of the deposit between 400 and $4000 \mathrm{~cm}^{-1}$. Several distinctive peaks appear on this spectrum. The two peaks at 563 and $713 \mathrm{~cm}^{-1}$ correspond to the vibration of $\mathrm{Mn}-\mathrm{O}$ according to Jin et al. [26], as reported by Wang et al. that bands in the region above $400 \mathrm{~cm}^{-1}$ are attributed to $\mathrm{Mn}-\mathrm{O}$ vibrations [28]. The peaks at $3100 \mathrm{~cm}^{-1}$ and at $1600 \mathrm{~cm}^{-1}$ correspond to the $\mathrm{O}-\mathrm{H}$ vibra-

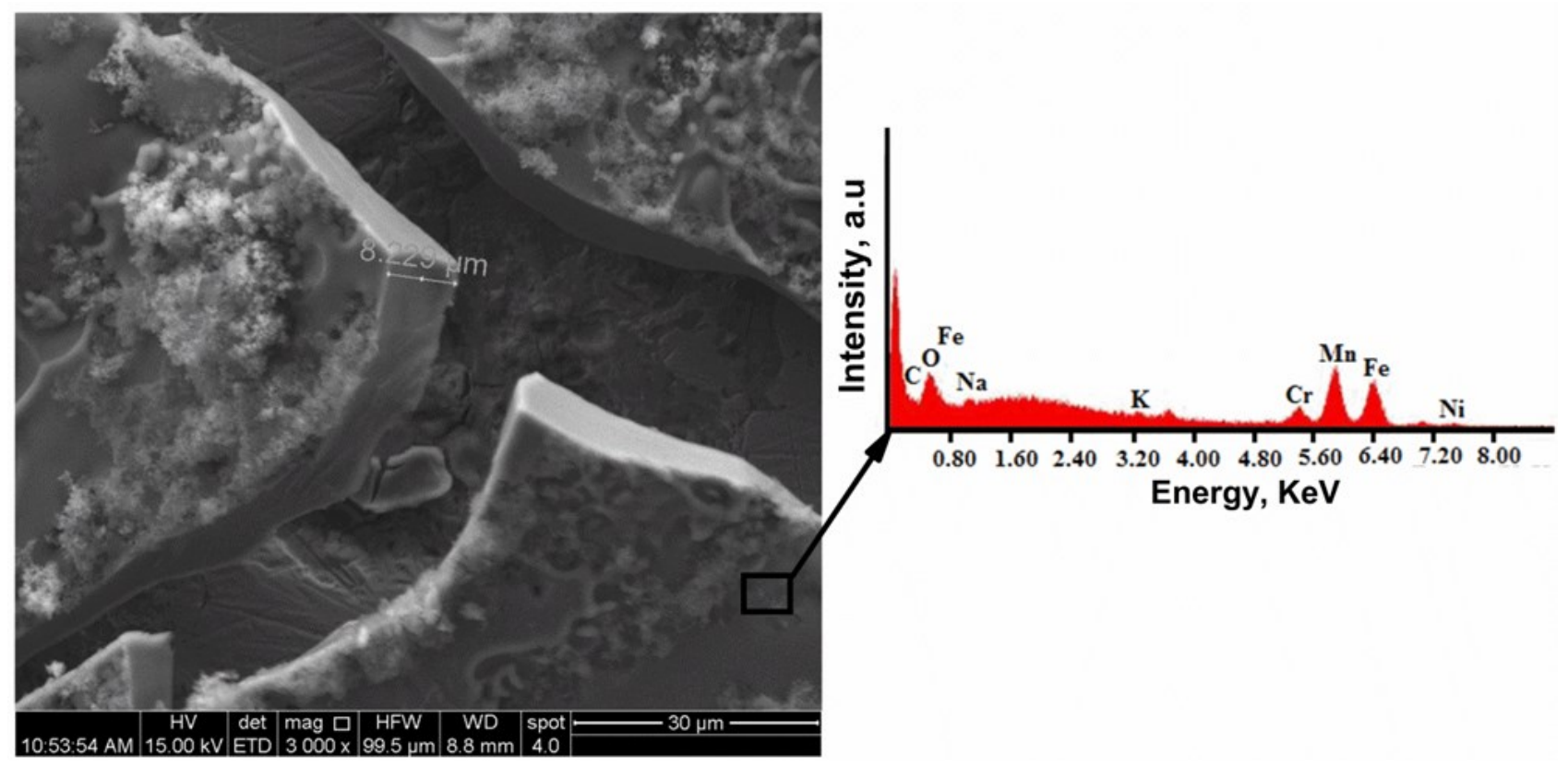

Figure 9. SEM micrograph with EDS analysis of the surface of $316 \mathrm{~L}$ stainles steelcovered by deposit layer.

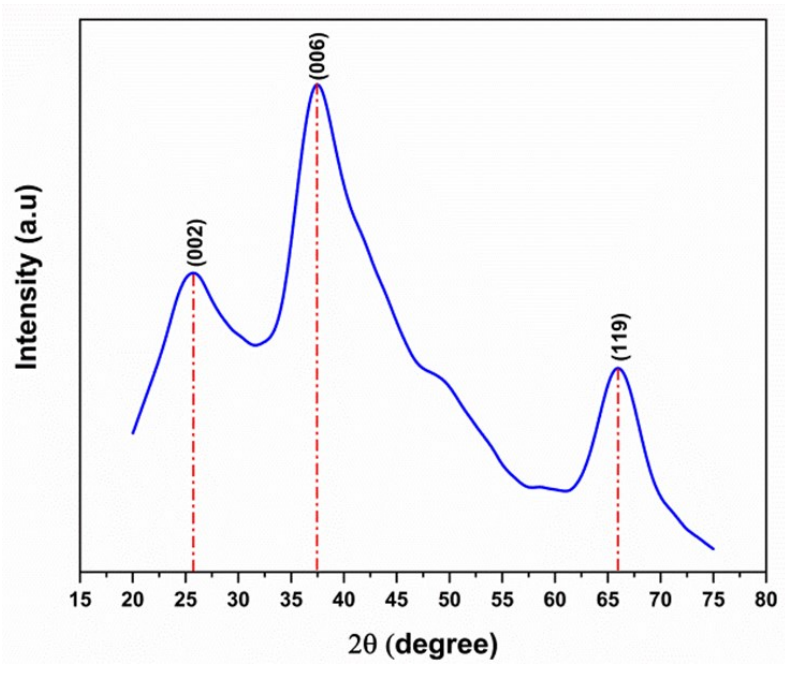

Figure 10. X-ray diffraction pattern of deposit.

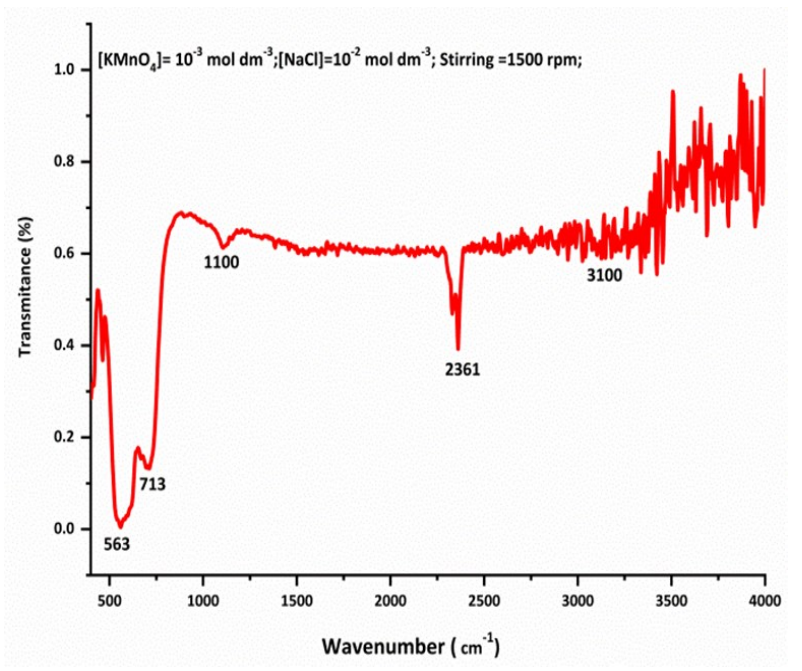

Figure 11. FTIR spectrum of the deposit. 
tion. This is due to the existing low humidity, despite the sample being dried in an oven at a temperature of $393 \mathrm{~K}$ for 24 hours. The peak at $1100 \mathrm{~cm}^{-1}$ corresponds to the $\mathrm{Mn}-\mathrm{OH}$ vibration according to Dubal et al. [29]. The existence of the peak at $2361 \mathrm{~cm}^{-1}$ is related to the carbonate fragments observed during an open-air FTIR analysis [30].

Figure 12 present the Differential Scanning Calorimetry (DSC) curve, it shows the enthalpy change of the deposit according to temperature. We can see, the endothermic peak located at $423 \mathrm{~K}$ [31], can be attribute to the loss of existing water in the sample. The three exothermic peaks appearing at 598,679, and $800 \mathrm{~K}$, are characteristic and correspond to the transformation of the $\delta-\mathrm{MnO}_{2}$ phase, to $\mathrm{Mn}_{2} \mathrm{O}_{3}$ and $\mathrm{Mn}_{3} \mathrm{O}_{4}$ then to $\mathrm{MnO}$, respectively [32,33]:

$$
\delta \mathrm{MnO}_{2} \stackrel{I}{\longrightarrow} \mathrm{Mn}_{2} \mathrm{O}_{3} \stackrel{I I}{\longrightarrow} \mathrm{Mn}_{3} \mathrm{O}_{4} \stackrel{I I I}{\longrightarrow} \mathrm{MnO}
$$

\section{Conclusions}

In this work we are interested to study the inhibition efficiency of permanganate ions as corrosion inhibitor of $316 \mathrm{~L}$ stainless steel using rotating disk electrode. In presence of permanganate ions, the cathodic reduction reactions lead to a considerable displacement of the OCP to positive potentials and the formation of a deposit protecting layer, this result is confirmed by (EIS) where the $R_{c t}$ increases with immersion time, indicating the growth of deposit layer. Stirring speed promotes the appearance of reduction peak of permanganate to manganese oxide at $+0.465 \mathrm{~V}$ us SCE, this contributes to the anodic displacement of the pitting potential. For smallest concentration of permanganate $10^{-4} \mathrm{~mol} . \mathrm{dm}^{-3}$, the inhibition efficiency is up to $98 \%$. Increasing the permanganate ions concentration improves the stainless steel's re-

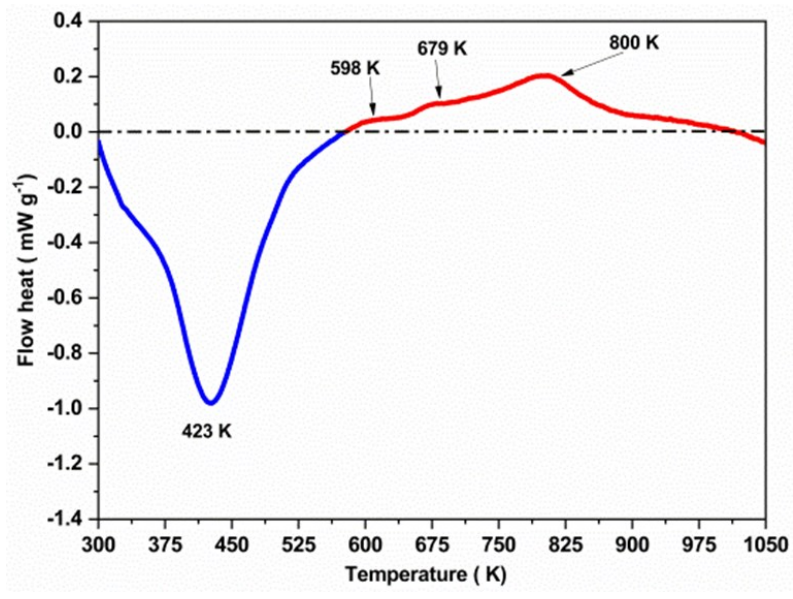

Figure 12. DSC curve of the deposit. sistance to pitting corrosion which is reflected by anodic displacement of pitting potential. At high temperatures, the pitting potential shifts cathodically, making the surface more vulnerable to pitting corrosion, which requires further investigation for its use in cooling circuits. Whatever the $\mathrm{pH}$ of medium, permanganate ions are reduced to $\mathrm{MnO}_{2}$. The characterization of deposit layer by X-ray diffraction shows the formation of a single form of the manganese oxide $\delta-\mathrm{MnO}_{2}$, with average crystallite size and micro strain: $3.17 \mathrm{~nm}$ and $4.24 \%$, respectively.

\section{Acknowledgements}

The authors thank the Birine Nuclear Research Centre, Djelfa, Algeria for supporting this work.

\section{References}

[1] Björn, W. (2018). Systemic thinking in support of safety management in nuclear power plants. Safety Science, 109, 201-218. DOI: 10.1016/j.ssci.2018.06.001.

[2] Sung-Wan, K., Bub-Gyu, J., Dae-Gi, H., MinKyu, K. (2020). Ratcheting fatigue failure of a carbon steel pipe tee in a nuclear power plant using the deformation angle. Engineering Failure Analysis, 114, 104595. DOI: 10.1016/j.engfailanal.2020.104595.

[3] Boucherit, M.N., Amzert, S., Arbaoui, F., Sari, A., Tebib, D. (2006). Study of the evolution of a semi-open cooling circuit. Anti-Corrosion Methods and Materials, 53(4), 212-217. DOI: 10.1108/00035590610678901.

[4] Varga, K., Németh, Z., Szabó, A., Radó, K., Oravetz, D., Homonnay, Z., Schunk, J., Tilky, P., Kőrösi, F. (2006). Comprehensive investigation of the corrosion state of the heat exchanger tubes of steam generators. Part I. General corrosion state and morphology. Journal of Nuclear Materials, 348(1), 181190. DOI: 10.1016/j.jnucmat.2005.09.012.

[5] Boucherit, M.N., Amzert, S., Arbaoui, F., Hanini, S., Hammache, A. (2008). Pitting corrosion in presence of inhibitors and oxidants. Anti-Corrosion Methods and Materials, 55(3), 115-122. DOI: 10.1108/00035590810870419.

[6] Zhao, J., Yang, Q., Zhang, C., Wang, Y. (2019). Corrosion of N80 Steel in a Concentrated Tetrapotassium Pyrophosphate Solution and Corrosion Control by Vanadates. International Journal of Electrochemical Science, 14, 6209-6222. D O I : 10.20964/2019.07.35.

[7] Zhang, P., Chen, Y., Huang, H., Zhou, Y., Yan, F., Nie, G. (2020). Surface Passive Film Characteristic Of Q235 Carbon Steel In Pure 
Molybdate Solution. Surface Review and Letters, $27 \quad(05), \quad 1950179$, DOI: $10.1142 / \mathrm{S} 0218625 \mathrm{X} 19501798$

[8] Zhang, P., Chen, Y., Zhou, Y., Yan, F., Nie, G. (2021). Electrochemical Investigation of the Synergistic Effect Between Molybdate and Tungstate on Surface Passivation of Carbon Steel. International Journal of Electrochemical Science, 16, 151027. DOI: 10.20964/2021.01.49.

[9] Agrawal, V.K., Bansal, A., Kumar, R., Kumawat, B.L., Mahajan, P. (2014). Potassium permanganate toxicity: A rare case with difficult airway management and hepatic damage. Indian Journal of Critical Care Medicine, 18(12), 819-821. DOI: 10.4103/09725229.146318 .

[10] Sung-Mao, H., Han, L., Huan-Wen, C., SiaoYing, C., Chao-Sung, L. (2021). Corrosion resistance and electrical contact resistance of a thin permanganate conversion coating on dual-phase LZ91 Mg-Li alloy. Journal of Materials Research and Technology, 11, 19531968. DOI: 10.1016/j.jmrt.2021.02.050.

[11] Madden, S.B., Scully, J.R. (2014). Inhibition of AA2024-T351 corrosion using permanganate. Journal of the Electrochemical Society, 161(3), C162-C175. DOI: 10.1149/2.075403jes

[12] Sun, B., Zhang, Y., Gong, Z., Zhang, J., Zhang, J. (2021). Reducing substancesenhanced degradation of pollutants by permanganate: The role of in situ formed colloidal MnO2. Chemosphere, 130203. DOI: 10.1016/j.chemosphere.2021.130203.

[13] Tazwar, G., Devra, V. (2020). Soluble colloidal manganese dioxide: Formation, characterization and application in oxidative kinetic study of ciprofloxacin. Bulletin of Chemical Reaction Engineering \& Catalysis, 15(1), 74-83. DOI: 10.9767/bcrec.15.1.5436.74-83.

[14] Subramanian, V., Chandramohan, P., Srinivasan, M.P., Velmurugan, S., Narasimhan, S.V. (2007). Corrosion of cupronickel alloy in permanganate under acidic condition. Corrosion Science, 49(2), 620-636. DOI: 10.1016/j.corsci.2006.06.001.

[15] Osipenko, M.A., Kharitonov, D.S., Makarova, I.V., Wrzesińska, A., Kurilo, I.I. (2020). The Effect of Sealing with Potassium Permanganate on Corrosion Resistance of Anodized AD31 Aluminum Alloy. Protection of Metals and Physical Chemistry of Surfaces, 56, 990997. DOI: 10.1134/S2070205120050214.

[16] Yanqi, W., Gang, K. (2020). Corrosion inhibition of galvanized steel by $\mathrm{MnO} 4$ - ion as a soluble inhibitor in simulated fresh concrete environment. Construction and building materials, $\quad 257, \quad 119532$. D O I : 10.1016/j.conbuildmat.2020.119532.
[17] Amzert, S.A., Hanini, S., Boucherit, M.N. (2013). Influence of permanganate reduction on CaCO3 crystals' growth on a rotating metal surface. Journal of Crystal Growth, 382, 15-20. DOI: 10.1016/j.jcrysgro.2013.07.033.

[18] Wang, Z., Seyeux, A., Zanna, S., Maurice, V., Marcus, P. (2020). Chloride-induced alterations of the passive film on $316 \mathrm{~L}$ stainless steel and blocking effect of pre-passivation. Electrochimica Acta, 329, 135159. DOI: 10.1016/j.electacta.2019.135159.

[19] Orouji, S. M., Naderi, R., Mahdavian, M. (2020). Controlled oxidation of mild steel by potassium permanganate solution to enhance protective functioning of silane coatings. Colloids and Surfaces A: Physicochemical and Engineering Aspects, 603, 125251. DOI: 10.1016/j.colsurfa.2020.125251.

[20] Cotton, F.A., Wilkinson G. (1980). Advanced Inorganic Chemistry, third ed., New York: John Wiley and Sons.

[21] Kuznetsov, Y.I. (2000). Corrosion inhibitors in conversion coatings. II. Protection of Metals, $\quad 36(2), \quad 128-134$. D O I : 10.1007/BF02758335.

[22] Pourbaix, M. (1974). Atlas of electrochemical equilibria in aqueous solution. Edition NACE.

[23] Boytsova, O.V., Shekunova, T.O., Baranchikov, A.E. (2015). Nanocrystalline manganese dioxide synthesis by microwavehydrothermal treatment. Russian Journal of Inorganic Chemistry, 60(5), 546-551. DOI: 10.1134/S0036023615050022.

[24] Yan, J., Wei, T., Cheng, J., Fan, Z., Zhang, M. (2010). Preparation and electrochemical properties of lamellar $\mathrm{MnO} 2$ for supercapacitors. Materials Research Bulletin, 45(2), 210-215. DOI: 10.1016/j.materresbull.2009.09.016.

[25] Marafatto, F.F., Lanson, B., Peña, J. (2018). Crystal growth and aggregation in suspensions of $\delta-\mathrm{MnO} 2$ nanoparticles: implications for surface reactivity. Environmental Science: Nano, 5(2), 497-508. DO I : 10.1039/C7EN00817A.

[26] Jin, H., Yuan, J., Hao, H., Ji, Z., Liu, M., Hou, S. (2013). The exploration of a new adsorbent as $\mathrm{MnO} 2$ modified expanded graphite. Materials Letters, 110, 69-72. DOI: 10.1016/j.matlet.2013.07.042.

[27] Abdeen, D.H., Atieh, M.A., Merzougui, B. (2021). Corrosion Behaviour of 316L Stainless Steel in CNTs-Water Nanofluid: Effect of Temperature. Materials, 14(1), 119. DOI: 10.3390/ma14010119.

[28] Wang, Y., Wu, W., Cheng, L., He, P., Wang, C., Xia, Y. (2008). A Polyaniline-Intercalated Layered Manganese Oxide Nanocomposite Prepared by an Inorganic/Organic Interface 
Reaction and Its High Electrochemical Performance for Li Storage. Advanced Materials, $20(11), \quad 2166-2170$. D O I : 10.1002/adma.200701708.

[29] Dubal, D.P., Lokhande, C.D. (2013). Significant improvement in the electrochemical performances of nano-nest like amorphous $\mathrm{MnO} 2$ electrodes due to $\mathrm{Fe}$ doping. Ceramics International, 39(1), 415-423. DOI: 10.1002/adma.200701708.

[30] Lili, W.U., Youshi, W.U., Yuanchang, S.H.I., Huiying, W.E.I. (2006). Synthesis of $\mathrm{ZnO}$ nanorods and their optical absorption in visiblelight region. Rare Metals, 25(1), 68-73. DOI: 10.1016/S1001-0521(06)60017-X.
[31] Arbaoui, F., Boucherit, M.N. (2014). Comparison of two Algerian bentonites: Physicochemical and retention capacity study. $A p$ plied Clay Science, 91, 6-11. DOI: 10.1016/j.clay.2014.02.001.

[32] Dose, W.M., Donne, S.W. (2011). Manganese dioxide structural effects on its thermal decomposition. Materials Science and Engineering: $B, \quad 176(15), \quad 1169-1177 . \quad$ DOI: 10.1016/j.mseb.2011.06.007.

[33] Terayama, K., Ikeda, M. (1983). Study on thermal decomposition of $\mathrm{MnO}_{2}$ and $\mathrm{Mn}_{2} \mathrm{O}_{3}$ by thermal analysis. Transactions of the Japan Institute of Metals, 24(11), 754-758. DOI: 10.1016/j.mseb.2011.06.007. 